\title{
PARAMETER EXTRACTION AND ESTIMATION BASED ON THE PV PANEL OUTDOOR PERFORMANCE USING ITERATIVE METHOD
}

\author{
Ali, M. H. ${ }^{1}$ and Yusuf, A. ${ }^{2, *}$ \\ ${ }^{1}$ Department of Physics, Bayero University, Kano-Nigeria \\ ${ }^{2}$ Department of Physics, Kaduna State University, Kaduna-Nigeria \\ * Corresponding author: aybbabascience@gmail.com ; Tel.:+2348039735020.
}

ABSTRACT

This work presents a novel approach to predict the voltage-current (V-I) characteristics of a $P V$ panel under varying weather conditions to estimate the PV parameters. Outdoor performance of the PV module (AP-PM-15) was carried out for several times. The experimental data obtained are validated and compared with the estimated results obtained through simulation based on the manufacture's data sheet. The simulation is based on the Newton-Raphson iterative method in MATLAB environment. This approach aids the computation of the PV module's parameters at any varying weather condition. The computed significant error indicates that the result has a good agreement with the experimental data. Keyword: Newton-Raphson, Parameter extraction, Simulation, Photovoltaic, Relative error

\section{INTRODUCTION}

Photovoltaic (PV) energy is currently undergoing rapid development worldwide. Nowadays the worldwide installed Photovoltaic power capacity indicates a practically exponential increase, despite of their still fairly high cost (Jack, Salam, \& Ishaque, 2015). This, along with the research for lower cost and higher efficiency devices, motivates the researchers to aim at achieving higher efficiency and reliability.

The possibility of predicting a photovoltaic array's performance in various irradiance and temperature, is very important for sizing the PV arrays as well as for the design of the Maximum Power Point Tracking (MPPT) and control strategy (Ali \& Yusuf, 2015; Sera, Teodorescu, \& Rodriguez, 2007). There are several methods offered in the literature for extracting the panel parameters. The majority of the methods are based on measurements of the I-V characteristic of the panel (Jack et al., 2015). The main aspect of PV simulation that requires attention is the estimation of the model parameters. In general, the manufacturer's datasheets only tabulate the open circuit voltage $\left(V_{o c}\right)$, short circuit current $\left(\mathrm{I}_{\mathrm{gc}}\right)$, MPP current $\left(I_{M P}\right)$ voltage $\left(V_{M P}\right)$ and maximum power point $\left(\boldsymbol{P}_{M P}\right)$. In some cases, the values of the temperature coefficients for open circuit voltage $(K v)$ and short circuit current $(\mathrm{Ki})$ are also specified.

Despite the availability of these data, unfortunately, they differ from what is required by the model. The latter is based on circuit variables, such as the photocurrent (IPV), saturation current $\left(I_{0}\right)$, diode ideality factors $(A)$, series $\left(R_{s}\right)$ and shunt $\left(R_{s h}\right)$ resistances. Thus, the datasheet information must be interpreted to parameters that can be computed by the model. Furthermore, the datasheet provides data at (STC), whereas a typical PV system operates at environmental conditions far from that condition (Chouder, Silvestre, Sadaoui, \& Rahmani, 2012).

The main objective of this paper is to subject the panel into outdoor performance, compare the characteristics and to evaluate the module parameters at outdoor performance.

Modeling of photovoltaic systems

Figure (1) depicts the equivalent circuit of the photovoltaic (PV) cell empirical model whose basic fundamental current-voltage governing equation is given by equation (1) (Hasan \& Parida, 2016);

$I=I_{p h}-I_{0}\left\{\exp \left(\frac{V+R_{s} I}{A}\right)-1\right\}-\frac{V+R_{s} I}{R_{s h}}$ (1) 


\section{Special Conference Edition}

where $I_{p h}$ is the photocurrent in $(\mathrm{A}), I_{0}$ is the diode saturation current (A), $A=n k T / q$ modified ideality factor, $\boldsymbol{n}$ the diode ideality factor, $\boldsymbol{k}$ the Boltzmann constant, $\boldsymbol{q}$ the electronic charge, $\boldsymbol{R}_{\boldsymbol{s}}$ the series resistance, $\boldsymbol{R}_{\boldsymbol{s h}}$ is the shunt resistance, $T$ is the cell absolute temperature.

The nonlinear and implicit equation given by Equation (1) would be solved using the Newton Raphson iterative method (Hasan \& Parida, 2016; Jena \& Ramana, 2015). The five parameters in Equation (1) depend on the incident solar irradiance, the cell temperature, and on their reference values. These reference values are generally provided by manufacturers of PV modules for specified operating condition such as STC (Standard Test Conditions) for which the irradiance is $1000 \mathrm{~W} / \mathrm{m}^{2}$ and the cell temperature is $25^{\circ} \mathrm{C}$. Real operating conditions are always different from the standard conditions, and mismatch effects can also affect the real values of these parameters. So the evaluation of the five parameters in real conditions of work is of prime interest in this work to provide an accurate PV module mathematical model. Furthermore, the reference parameters given by the manufacturer at standard temperature condition (STC) are not accurate for outdoor conditions. Thus, a procedure based on outdoor measurement and mathematical formulation to determine the reference values of these parameters is recommended. The evaluation of the five model parameters at real condition of irradiance and temperature of the target PV module would be determined according to their reference values (Chouder et al., 2012).

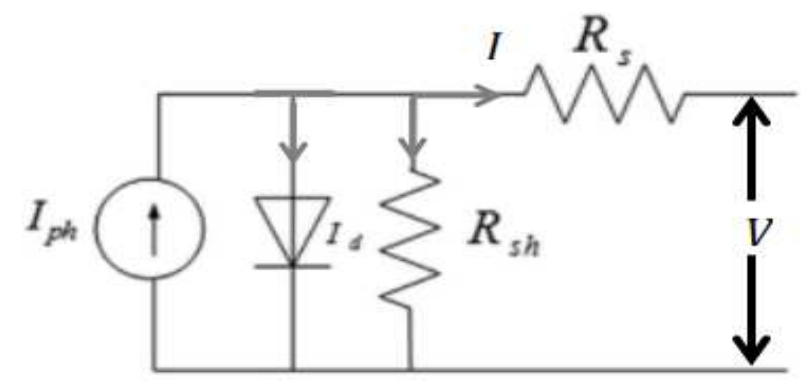

Figure 1.0: Equivalent Electrical circuit of the single diode model

Newton Raphson Estimation Method

Newton Raphson Method is an iterative method that consists in estimate of a given function $f(x)$ with an initial guess. The method is obtained through the Taylor series expansion in $\left(x-x_{0}\right)$ given below;

$f(x)=f\left(x_{0}\right)+f^{\prime}\left(x_{0}\right)\left(x-x_{0}\right)+\frac{1}{2} f^{\prime \prime}\left(x_{0}\right)\left(x-x_{0}\right)^{2}+\cdots=0$

Restricting the series in the second term one can obtain the general formula of Newton Raphson's method as given by equation (3) (Obbadi, Errami, El, \& Agunaou, 2016)

$x_{1}=x_{n}-\frac{f\left(x_{0}\right)}{f^{\prime}\left(u_{0}\right)}$

The corresponding equivalent for the nonlinear equation (1) can be written as;

$$
I_{n+1}=I_{n}-\frac{I_{p h}-L_{n}-I_{0}\left(\exp \left(\frac{V+I_{n} R_{s}}{A N_{s} V_{t}}\right)-1\right)}{-1-\frac{I_{g} R_{s}}{A N_{s} V_{t}}\left(\exp \left(\frac{V+I_{n h} R_{s}}{A V_{s} V_{t}}\right)-1\right)}
$$

In this nonlinear equation, this method presents an easy and precise way to reduce the number of equations to four by modifying the resistance $R_{S}$. The resistances $R_{S}$ and $R_{s h}$ can then be calculated from the fact that only an exclusive pair of these two parameters gives the maximum power at every operating Ideality factor, A, given as;

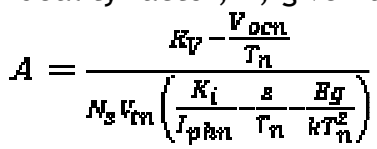

where $\mathrm{Eg}$ is the band gap energy of the junction. At maximum power the shunt resistance $\boldsymbol{R}_{s h}$ can be calculated using equation (6) below (Shongwe \& Hanif, 2015); 


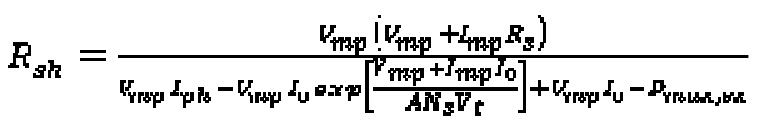

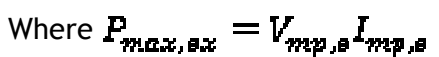

$$
\begin{aligned}
& I_{0}=\frac{i_{g c m}+R_{i} d T}{\left(\frac{T_{0 c h} R_{V} d T}{A N_{S} V_{t}}\right)-1} \\
& I_{p h}=\left(I_{p m}+K_{i} d T\right) \frac{G}{G_{m}}
\end{aligned}
$$

Assumes that $V_{\mathrm{DE}}, I_{s c}$ depend on temperature $(T)$ and the irradiance $(G)$ then, new equation relating $V_{\mathrm{Den}}$ with $V_{c e}$ and $I_{s e n}$ with $I_{s e}$ are written as given by (Reis, Camacho, \& Novacki, 2017; Shongwe \& Hanif, 2015) can be used to estimate the irradiance,

$$
\begin{aligned}
& V_{\mathrm{oc}}=V_{\mathrm{cen}}+K_{V} d T+A V_{\mathrm{t}} N_{s} \ln \left(\frac{G}{G_{\mathrm{Tl}}}\right) \\
& I_{s \mathrm{~s}}=\left(\frac{G}{G_{\mathrm{y}}}\right)\left(I_{s a m}+K_{\mathrm{i}} d T\right)
\end{aligned}
$$

\section{MATERIALS AND METHOD}

The current-voltage characteristic of the panel (AP$P M-15)$ was investigated using the circuit on figure (2). Adjusting the rheostat until voltage reading is zero and recording the short circuit current as $I_{s e}$, disconnecting the rheostat $(50 \Omega)$ from the circuit, current becomes zero and then recording the open circuit voltage $V_{o c}$. Varying the Rheostat between these pairs of values and recording the corresponding voltages and currents. Time, date irradiance and location of the experiment where also recorded.

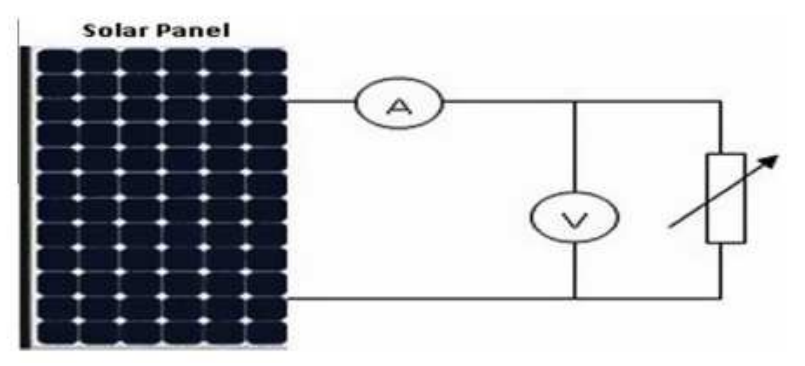

Figure 2: Experimental setup.

\section{RESULTS AND DISCUSSIONS}

The above equations were implemented in MATLAB environment, both the simulation and the experimental data were plotted analyzed and compared.The experimental data and the simulation results of the photovoltaic were compared graphically, see Figure 3-6, the result were also

\begin{tabular}{|c|c|c|}
\hline 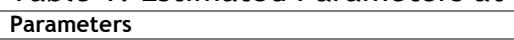 & Data sheet value & Estimated value \\
\hline $\operatorname{Isc}$ & 0.95 & 0.95 \\
\hline Voc & 22.05 & 22.05 \\
\hline $\operatorname{mpp}(A)$ & 0.85 & 0.8751 \\
\hline vmpplr) & 17.5 & 17.1 \\
\hline$P \max (W)$ & 14.875 & 14.9642 \\
\hline Ideality Factor, A & - & 1.3267 \\
\hline Diode saturation current & & $8.927 \times 10^{-8}$ \\
\hline Series Resistance $(\boldsymbol{Q})$ & - & 2.194 \\
\hline Shunt resistance ( $(D)$ & $\cdot$ & $1.38 \times 10^{6}$ \\
\hline $\boldsymbol{H}_{\mathrm{i}}(0 / / \mathrm{C})$ & 0.06 & - \\
\hline $\boldsymbol{K}_{\boldsymbol{v}}\left(0 / 6 /{ }^{\circ} \mathrm{C}\right.$ & 11.23 & - \\
\hline
\end{tabular}
recorded as can be seen on table 2 . In can be seen that the five parameters increase with temperature

Table 1: Estimated Parameters at STC and irradiance with the exception of Series resistance, where a decrease was observed. This is in agreement with the other methods used in parameter extraction in outdoor performance as proposed in (Muralidharan, 2016; Vengatesh \& Rajan, 2011; Yusuf \& Ali, 2016). The relative error were observed to be less than $3 \%$ in all the experiment conducted. 


\section{Special Conference Edition}

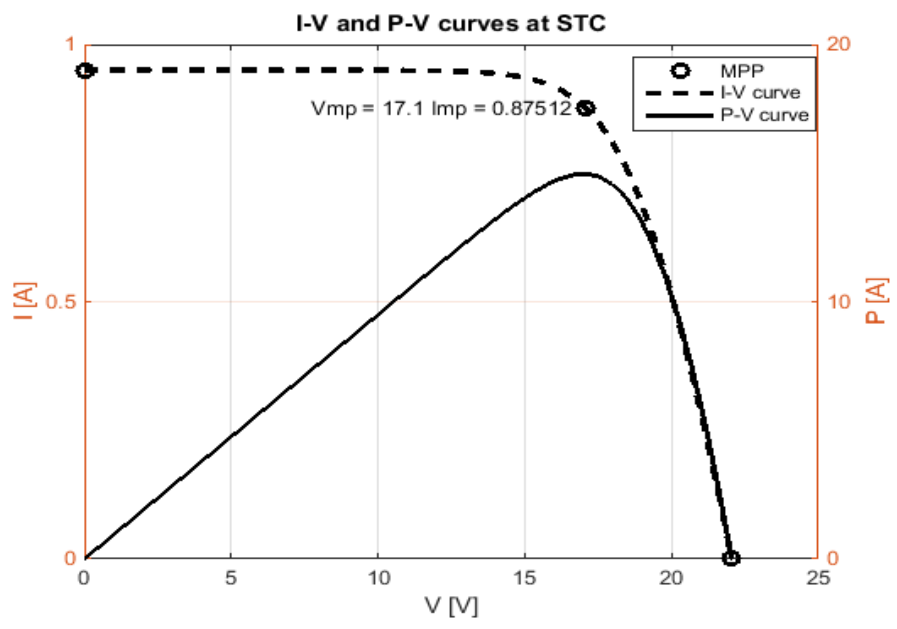

Figure $3: \mathrm{I}-\mathrm{V}$ and P-V rurves at STC.

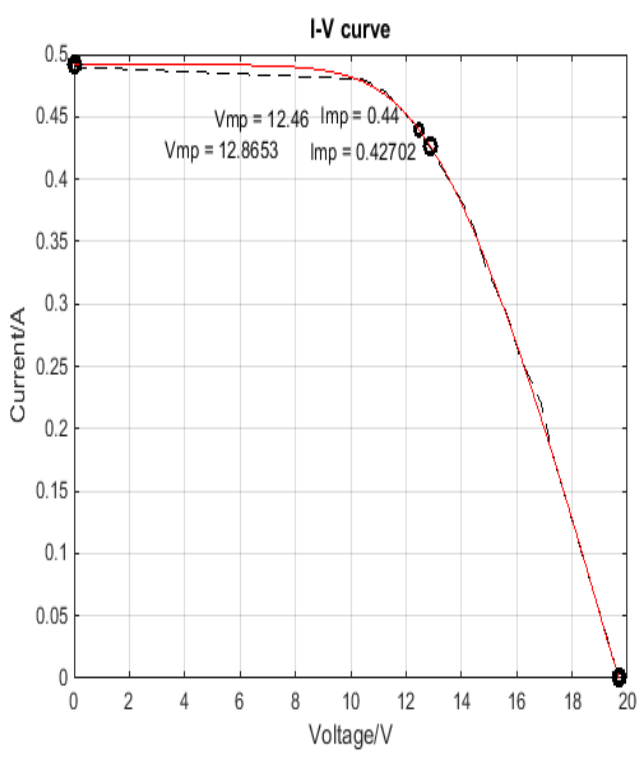

(a)

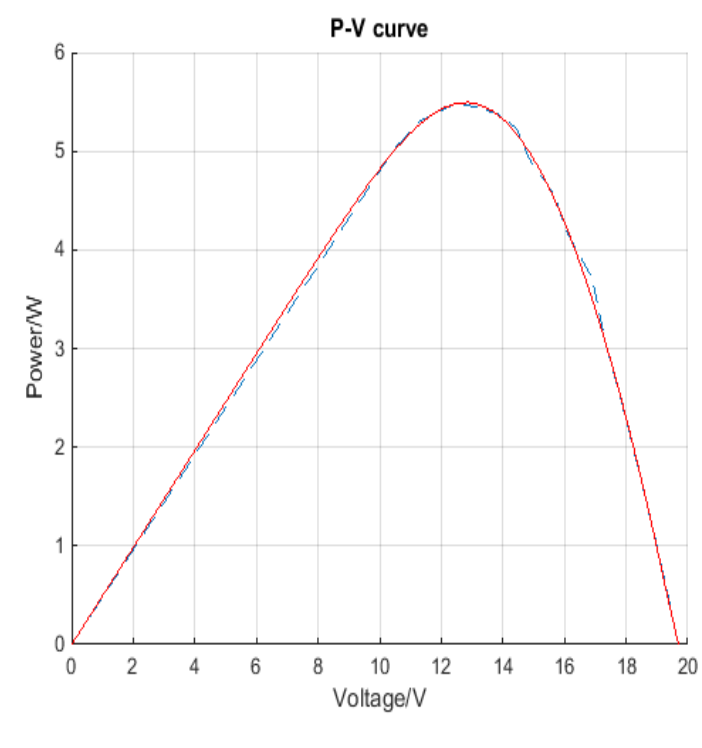

(b)

Figure 4: Characteristics curves for experimental and simulated values (a) I-V curve (b) P-V curve

Date: $19 / 04 / 2017$

Time: 9:20am

$\mathrm{T}=39^{\circ} \mathrm{C}$

$G=513.4 W / m^{2}$ 


\section{Special Conference Edition}

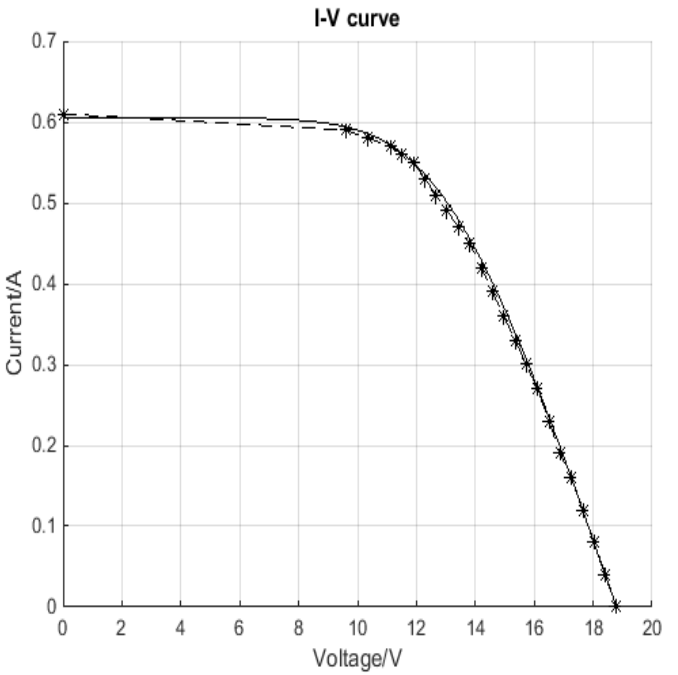

(a)

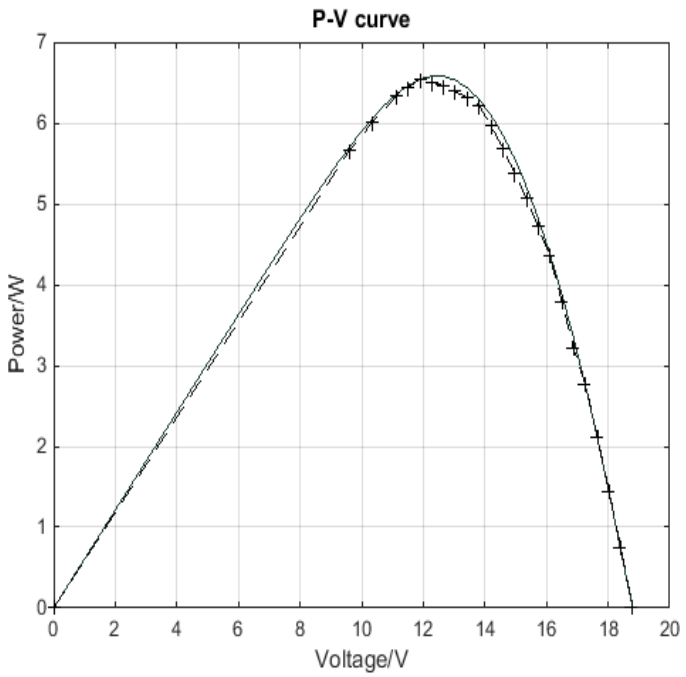

(b)

Figure 5: Characteristics curves for experimental and simulated values (a) I-V curve (b) P-V curve

Table 2: Result from the experiments and the simulations.

\begin{tabular}{lcccccc}
\hline & \multicolumn{5}{c}{ Experiment } & \multicolumn{3}{c}{ Simulation } \\
Parameters & $\mathbf{1}$ & $\mathbf{2}$ & $\mathbf{3}$ & $\mathbf{1}$ & $\mathbf{2}$ & $\mathbf{3}$ \\
\hline $\mathrm{I}_{\mathrm{sc}}$ & 0.49 & 0.61 & 0.55 & 0.4900 & 0.6056 & 0.5450 \\
$\mathrm{~V}_{\text {oc }}$ & 19.7 & 18.8 & 19.41 & 19.7 & 18.8 & 19.41 \\
$\mathrm{~T}_{\text {panel }}$ & 39 & 49 & 42.5 & 39 & 49 & 42.5 \\
$\mathrm{I}_{\text {mpp }}(\mathrm{A})$ & 0.44 & 0.55 & 0.44 & 0.4270 & 0.5358 & 0.4787 \\
$\mathrm{~V}_{\text {mpp }}(\mathrm{V})$ & 12.46 & 11.89 & 13.94 & 12.8653 & 12.2776 & 13.0720 \\
$\mathrm{P}_{\text {max }}(\mathrm{W})$ & 5.4824 & 6.5395 & 6.1336 & 5.4935 & 6.5783 & 6.2576 \\
${\text { Irradiance }\left(\mathrm{W} / \mathrm{m}^{2}\right)}$ & - & - & - & 513.40 & 628.41 & 567.97 \\
Ideality Factor, $\mathrm{A}$ & - & - & - & 1.3046 & 1.3075 & 1.3062 \\
Series Resistance $(\Omega)$ & - & - & - & 10.08 & 6.9840 & 7.7180 \\
Shunt resistance $(\Omega)$ & - & - & - & $1.2169 \times 10^{6}$ & $4.1550 \times 10^{7}$ & $9.8424 \times 10^{5}$ \\
$\mathrm{I}_{\text {pv }}(\mathrm{A})$ & & & & 0.4918 & 0.6057 & 0.5450 \\
$\mathrm{I}_{\mathrm{o}}(\mathrm{A})$ & & & & $5.5048 \times 10^{-8}$ & $2.3294 \times 10^{-7}$ & $9.2873 \times 10^{-8}$ \\
\hline
\end{tabular}

\section{CONCLUSION}

In this paper, the Newton-Raphson iterative method for PV module parameters extraction was described. The five parameters extracted used outdoor performance with the empirical equations to predict the module I-V and P-V characteristics for operating conditions other

\section{REFERENCES}

Ali, M. H., \& Yusuf, A. (2015). Performance Analysis of Different Photovoltaic Technologies Based on MATLAB Simulation. In Northwest University Science, Faculty of Science Annual International Conference. than the STC. The relative error associated with the simulation results obtained shows that the simulation results are in good agreement with the experimental data at real working condition and justify its use for deeper investigation on the characteristics of photovoltaic modules.

Chouder, A., Silvestre, S., Sadaoui, N., \& Rahmani, L. (2012). Modeling and simulation of a grid connected PV system based on the evaluation of main PV module parameters. Simulation Modelling Practice and Theory, 20(1), 46-58. 
https://doi.org/10.1016/j.simpat.2011. 08.011

Hasan, M. A., \& Parida, S. K. (2016). An overview of solar photovoltaic panel modeling based on analytical and experimental viewpoint. Renewable and Sustainable Energy Reviews, 60, 75-83.

https://doi.org/10.1016/j.rser.2016.01 .087

Jack, V., Salam, Z., \& Ishaque, K. (2015). Cell modelling and model parameters estimation techniques for photovoltaic simulator application: A review. Applied Energy, 154, 500-519. https://doi.org/10.1016/j.apenergy.20 15.05.035

Jena, D., \& Ramana, V. V. (2015). Modeling of photovoltaic system for uniform and non-uniform irradiance: A critical review. Renewable and Sustainable Energy Reviews, 52, 400-417. https://doi.org/10.1016/j.rser.2015.07 .079

Muralidharan, R. (2016). Parameter Extraction of Solar Photovoltaic Cells and Modules Using Current-Voltage Characteristics. International Journal of Ambient Energy, 750(January). https: / /doi.org/10.1080/01430750.201 6.1144525

Obbadi, A., Errami, Y., El, A., \& Agunaou, M. (2016). Parameter estimation of photovoltaic modules using iterative method and the Lambert $\mathrm{W}$ function: A comparative
CONVERSION AND MANAGEMENT, 119, 37-48.

https://doi.org/10.1016/j.enconman.2 016.04.030

Reis, L. R. D., Camacho, J. R., \& Novacki, D. F. (2017). The Newton Raphson Method in the Extraction of Parameters of PV Modules. In nternational Conference on Renewable Energies and Power Quality (ICREPQ'17) Malaga (Spain), 4th to 6th April, 2017 Renewable Energy and Power Quality Journal (RE\&PQJ) ISSN 2172-038 X, No.15 April 2017 The (Vol. 1, pp. 634-639).

Sera, D., Teodorescu, R., \& Rodriguez, P. (2007). PV panel model based on datasheet values. IEEE Conference on Industrial Electronics and Applications, ICIEA, (4), 2392-2396.

Shongwe, S., \& Hanif, M. (2015). Comparative Analysis of Different Single-Diode PV Modeling Methods. IEEE JOUURNAL OF PHOTOVOLTAICS, 1-9. https://doi.org/10.1109/JPHOTOV.201 5.2395137

Vengatesh, R. P., \& Rajan, S. E. (2011). Investigation of cloudless solar radiation with PV module employing Matlab-Simulink. Solar Energy. https://doi.org/10.1016/j.solener.2011 .03 .023

Yusuf, I., \& Ali, M. H. (2016). Dynamic Estimation of Photovoltaic module Parameters using Differential Evolution. Bayero Journal of Physics and Mathematical Sciences, 7(1), 170-181. 